\title{
PROMOTING FOREIGN LANGUAGE LEARNERS' WRITING: COMPARING THE IMPACT OF ORAL CONFERENCING AND COLLABORATIVE WRITING
}

\author{
Mania Nosratinia \\ Islamic Azad University at Central Tehran, Iran \\ Email: mania_nosratinia@yahoo.com \\ Niousha Nikpanjeh \\ Islamic Azad University at Central Tehran, Iran \\ Email: nioushanikpanjeh@yahoo.com
}

\begin{abstract}
APA Citation: Nosratinia, M., \& Nikpanjeh, N. (2019). Promoting foreign language learners' writing: Comparing the impact of oral conferencing and collaborative writing. English Review: Journal of English Education, 7(2), 17-26. doi: 10.25134/erjee.v7i2.1772.
\end{abstract}

\begin{abstract}
This study is an attempt to compare the effect of oral conferencing alongside collaborative writing on writing skills of English as a Foreign Language (EFL) learner. For this purpose, a piloted sample of the Preliminary English Test (PET) was administered to 90 intermediate female EFL learners, between 20 and 32 years old $\left(\mathrm{M}_{\text {age }}=26\right)$. The results of this test enabled the researchers to select 60 homogenous individuals who were then randomly assigned into two experimental groups of 30 named "oral conferencing group" and "collaborative writing group". To ensure the homogeneity among the participants in terms of their writing ability before the treatment, their scores on the writing section of the PET test were analyzed in isolation and it was considered as the pretest of the study. Oral conferencing included the discussions and negotiations among the participants and the teacher before and after writing activities followed by live teacher-student as well as student-student feedbacks. In the collaborative writing group, the participants wrote compositions in groups based on the same topics introduced in the oral conferencing group. At the end, both groups were given another piloted writing section of the PET test as the posttest. The analysis of the test scores using an independent sample $t$-test and analysis of covariance (ANCOVA) revealed that there is a significant difference between the effect of oral conferencing and collaborative writing on EFL learners' writing skills. Finally, it can be concluded that EFL learners' writing skill was more affected by applying oral conferencing rather than collaborative writing.
\end{abstract}

Keywords: collaborative writing; EFL learners; oral conferencing; writing skill.

\section{INTRODUCTION}

Writing is regarded as an instrument through which people communicate with one another in time and space, transmitting their culture from one generation to another. Writing as one of the main and productive language skills, which was once considered as the domain of well-educated people, is becoming an essential tool for everyone in today's community (Cushing Weigle, 2002). In this perspective, writing as a significant requirement for EFL learners is regarded as one of the most important communicative skills in English language learning (Biria \& Jafari, 2013; Goodlet, \& Pymberton, 1989; Hayes \& Flower, 1986). Researchers have found that foreign language learners find it painstaking to write in the target language, producing less fluent sentences and encountering difficulties in the revisions of their written work (Fatemi, 2008; Hyland, 2003;
McCoy, 2003; Tan, 2007). However, these difficulties are not only attributed to their linguistic abilities, but they mostly lay in the nature of writing process itself (Chih, 2008).

Rooted in the ideas introduced in the process approach to writing, the provision of second party feedback, usually by the teacher, on learners' drafts is now given a higher level of attention (Williams, 2002). Accordingly, the provision of written corrective feedback on second/foreign language writing has been regarded as an integral component of writing programs (Mirzaii, 2012).

Oral conferencing is considered as one type of corrective feedback (Mirzaii, 2012). According to Bayraktar (2009), oral conferencing is identified and "referred to as response sessions, assisted performance, face-toface interaction, one-to-one teaching, conversation about the student's paper, and 
meaningful contact" (p. 11). Oral conferencing is advantageous in a way that teachers can foster learners' reflection on their own learning process; elicit language performances on particular tasks, skills, or other language points as well as helping them to develop a better selfimage (Brown \& Hudson, 1998).

Besides, oral conferencing is believed to assist teachers in creating a collaborative atmosphere, encouraging learners to actively engage in practicing writing (Ewert, 2009). Collaboration in writing has been drawing an increasing attention in language teaching and assessment (DiCamilla \& Anton, 1997; Storch, 2005; Swain \& Lapkin, 1998). According to Reither (1989), "thinking of writing as a collaborative process presents more precise ways to consider what writers do when they write, not just with their texts, but also with their language, their personae, and their readers" (p. 624). Collaborative writing requires learners to utilize a range of social skills that can help foster a sense of accountability, cooperation, and community (Murray, 1992; Savova \& Donato, 1991; Villamil \& De Guerrero, 1996). Moreover, collaborative writing, like any other collaborative activity, provides learners with the opportunity to give and receive immediate feedback on language, an opportunity which, as claimed by Vanderburg (2006), is "missing when learners write individually" (p. 378). Learners' working in groups, particularly in collaborative groups, constructs new ways of understanding and develops greater skills (Web, 1989).

However, writing is generally considered as an individual activity through which ideas are transferred from the writer's mind to the reader's. Therefore, quite few research has been conducted to examine the impact of corrective feedback on productive English skills, particularly writing. Hence, this study aimed to investigate the comparative effect of oral conferencing, as a type of corrective feedback, and collaborative writing on EFL learners' writing ability. To fulfill this objective, the problem raised in this study was formulated into the following research question: "Is there any significant difference between the impact of oral conferencing and collaborative writing on EFL learners' writing ability?". Accordingly, the following null hypothesis was formulated:

$H_{0}$ : There is no significant difference between the impact of oral conferencing and collaborative writing on EFL learners' writing ability.

\section{METHOD}

The 60 participants involved in this quasi experimental study were chosen from Hermes Institute in Tehran. They were female EFL learners at the intermediate level whose mother tongues was Persian and their age was between 20 to 32 years old $\left(M_{\text {age }}=26\right)$. They had been exposed to English courses for about 5 years in average. These participants were selected conveniently and homogenized through a piloted PET test among 90 learners. They were randomly assigned into two experimental groups of 30 named "oral conferencing group" and "collaborative writing group". To ensure the homogeneity among the participants of the two groups in terms of their writing ability before the treatment, their scores on the writing section of the PET test were analyzed in isolation and were used as the pretest scores of the participants. Both groups received the same amount of instruction. The course consisted of 10 sessions of 90 minutes spanning over a period of five weeks. Before administrating the PET test, a group of 30 students with almost similar characteristics -age, gender and proficiency level- to the target sample were used for the piloting of this test and the writing posttest. Here, one of the researchers (functioning as the teacher) tried to teach the relevant grammatical points as well as the essential vocabularies alongside of language skills with special focus on the writing skill. Participants were also given the same topics for their compositions and they were taught how to write a composition including introduction, body paragraphs, and conclusion. Compositions were rated according to the Jacobs et al.'s (1981) ESL Composition Profile by the one of the researchers (the teacher) and the other rater. In order to accomplish the purpose of the study, the following instruments were utilized:

1. The Preliminary English Test (PET) is now internationally recognized as a reliable test calibrated for the elementary level of English language proficiency. Being created by the University of Cambridge ESOL Examinations in England, the exam intends to be unbiased regarding test takers' linguistic backgrounds and nationalities. In addition to the knowledge of grammar and vocabulary, the PET test deals with all of the four skills of language, namely Reading, 
Writing, Listening, and Speaking. The PET test contains 125 items, and it takes 125 minutes to take the whole test. In the present study, however, the speaking section of the PET test was not used due to the limitations imposed by the institute officials.

2. The Writing Scale of PET - The employed rating scale for rating the PET test's writing section in the present study was created by Cambridge, called The General Mark Schemes for Writing. Using the criterion stated in this rating scale, the writing scores ranged from 0 to 5 .

3. Writing Pretest - In order to make sure that the participants in the two groups belonged to the same population in terms of writing ability, the participants' scores of the writing section of the PET test were analyzed in isolation and used as the writing pretest. This section consisted of three parts followed by 7 questions. The participants were required to fulfill the tasks of the test by using their lexical and syntactic abilities, such as writing letters, stories, and short messages.

4. Touchstone 3 - Touchstone, by Michael McCarthy, Jeanne McCarten, and Helen Sandiford (2005) has been published by the press syndicate of the University of Cambridge. This textbook is argued to offer an innovative and novel approach to EFL learning and teaching. Focusing on the North American English, this textbook has employed the Cambridge International Corpus which is composed of a huge amount of conversations and written texts. This book contains all language skills and sub-skills, and offers exciting ideas for personalized, learner-centered interaction. In this study, the students dealt with three units of the textbook, units 6, 7, and 8 .

5. Compositions - The participants were asked to write six compositions during the treatment sessions. They had 40 minutes to write about each predetermined argumentative topics. The topics of the compositions were the same across two experimental groups. The compositions consisted of 150 to 250 words and had to be written in descriptive voice. The compositions should have three parts; introduction, body paragraphs, and conclusion. In oral conferencing group, each student should write her composition at home. In each session, four or five students read their compositions in classroom. Contrary to oral conferencing group, the students in collaborative writing group were asked to write their compositions collaboratively in classroom.

6. Oral Conferencing Checklist - This checklist is designed by Moradan and Hedayati (2011). It contains a set of questions to be asked to all participants in oral conferencing group regarding pre and post writing activities during the treatment period. It is the result of discussions between the aforementioned researchers and their five coworkers in their study. It starts with some general questions regarding the participants' opinions about their writing abilities prior to the writing activity, and it ends with some questions about participants' ideas regarding their weaknesses and strengths in writing activity.

7. Jacobs, Zinkgraf, Wormuth, Hartfiel, and Hughey's (1981) ESL Composition ProfileThis instrument is an analytic scoring scale and consists of five subcategories of content, organization, vocabulary, language use, and mechanics. Each subcategory is in detail and the scoring system is clearly defined. The total score is calculated from 100 and the proportions of scoring are predetermined in the scale according to participants' performance in each part.

8. Writing Posttest - The posttest administered at the end of the study was the writing section of another version of PET. It was piloted in advance. This test was given to the participants for comparing the participants' writing ability in terms of the effect of both oral conferencing and collaborative writing.

\section{Oral conferencing group}

Oral conferencing in this study included the discussions and negotiations among the participants and the teacher before and after writing activities followed by live teacherstudent as well as student-student feedbacks. To do this, the Anderson Model (2000) and Oral Conferencing Checklist designed by Moradan and Hedayati (2011) were used.

Anderson (2000) as cited in (Bayraktar, 2009) states that teacher-student writing conferences generally fall into the following four types:

1) Rehearsal conferences which help students find idea to write about; 
2) Drafting conferencing which assists students develop their ideas and determine which genre and style they want to write in;

3) Revision conferences which help student improve their initial drafts; and

4) Editing conferences whose main focus lies in helping students become better editors.

Here, students should write their compositions at home. Based on the feedback they had already received regarding the conferences in the class, they would revise their writings. After completing the writing tasks, the students were asked to conference regarding their ideas, weaknesses, and strengths during the writing task.

The students in oral conferencing group were concentrated on the overall meaning and organization of their writing, and also on the vocabularies, language use, and the mechanics of writing. All the conferences conducted orally. Oral Conferencing Checklist designed by Moradan and Hedayati (2011) were used for this purpose. The teacher asked questions and gave students enough time to speak about their problems and to provide students with appropriate feedback.

\section{Collaborative writing group}

Whether to have students choose their own partners or they should be assigned at random into groups is the first major consideration in applying collaborative writing method (Mulligan \& Garofalo, 2011). Although instructors may present a better idea for matching students in groups, if the students choose their own partners themselves, it would be more effective for cooperative learning as a basic goal of collaborative writing (Cote, 2006). Based on this, the students were divided into 5 groups of 6 in order to write the assigned compositions and provide each other with feedback regarding their weaknesses and strengths.

Contrary to oral conferencing group, the students in collaborative writing group were asked to write their compositions collaboratively in classroom. In other words, all members of a group were responsible for making a final piece of writing. The same procedure which was used for familiarizing students in oral conferencing group with how to write a composition was also used for students in collaborative writing group. The teacher had to provide them with topic then they should go through the process of writing collaboratively which was based on the proposed steps of Mulligan and Garofalo (2011). Based on the requirements of this study and limitations which were imposed on the researchers by the institute officials, some modifications on the Mulligan and Garofalo's model (2011) was done as follows:

1) Students chose their partners themselves;

2) All the members of a group brainstormed ideas about the target topic and organized the information into coherent groupings;

3) All the members of a group did outlining, planning, and crafting;

4) The whole writing (composition) was read in the classroom by one of the members of the group;

5) The teacher checked the compositions based on Jacobs et al.'s (1981) ESL Composition Profile, and pointing out structural and organization errors, and providing the related group with comments and suggestions.

At the end of the treatment phase, the participants of both groups sat for the posttest which took about 55 minutes. The results of the test were then evaluated by the two raters based on the PET rating scale.

\section{RESULTS AND DISCUSSION}

This quasi experimental study was set out to compare the effect of oral conferencing and collaborative writing on EFL learners' writing ability. The independent variable has two modalities, oral conferencing and collaborative writing. The dependent variable is writing ability. The two control variables are the language proficiency and gender of the participants. In order to answer the research question proposed in this study, both descriptive and inferential statistics were taken in the piloting phase and administration, respectively.

Following the piloting of the PET test, the mean scores, the standard deviation of scores, and the reliability indices were calculated. This calculation demonstrated that the mean score was 53.24 and the standard deviation was 8.74. The item analysis revealed that there were two malfunctioning items in the test. After the deletion of the 2 malfunctioning items, the reliability of the test using Cronbach alpha was .94. The inter-rater reliability was calculated using the Pearson correlation coefficient, showing the existence of a significant correlation. Accordingly, the same raters could be used for rating the following administrations of the test.

After the procedure of piloting the PET test, it became an instrument to homogenize the 
students for this study. 90 EFL learners took part in the test administration. Following the administration, the descriptive statistics were calculated. This showed that the mean was 55.24 and the standard deviation was 9.20. The reliability of the PET test in this actual administration was .89 . In the next phase, the scores of the participants on the PET writing section were analyzed in isolation in order to inspect the homogeneity of the participants in the two groups before the treatment. The two groups' mean scores were almost the same (Oral conferencing $=10.6000$, Collaborative writing $=$ 10.0033). Thus, one can conclude that there was no noticeable difference between the means of the two groups at the outset of the study. Also, according to the results of a $t$-test, there was not a significant difference between the two experimental groups regarding their writing ability $(t(58)=.77, p>0.05)$ which confirms their homogeneity (Table 1).

Table 1. $t$-test results of experimental groups on writing pre-test

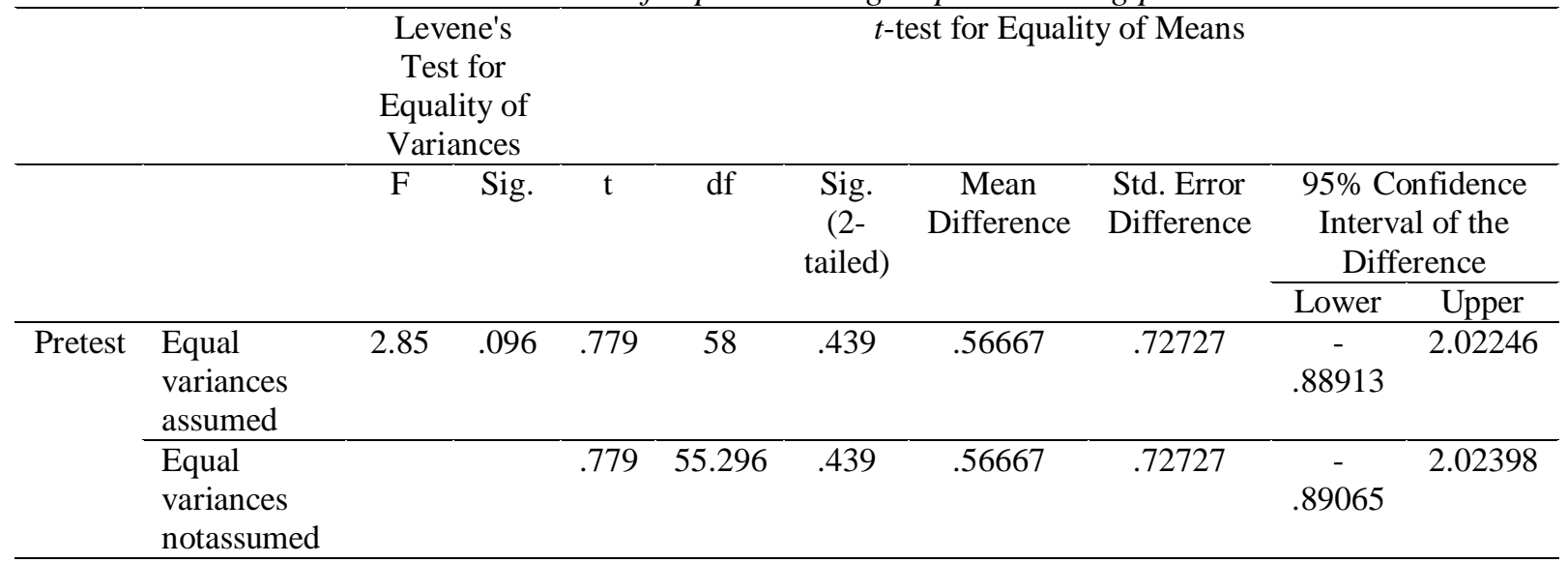

The results of the Pearson correlations indicated that there were significant agreements between the two raters who rated the subjects' writings on the posttest $(\mathrm{r}(58)=.94, p<.05$ representing a large effect size) for the writing part 2 and posttest of writing ( $\mathrm{r}(58)=.96, p<$ .05 representing a large effect size) for the writing part 3.

\section{Testing Assumptions}

In this study, the data were analyzed through an independent $t$-test and analysis of covariance (ANCOVA) which have two common assumptions; normality and homogeneity of variances. The latter will be discussed below when reporting the main results. As reported in Table 2, the skewness and kurtosis ratios were within the ranges of $+/-1.96$, confirming the normality of the data.

Table 2. Descriptive statistics of PET of the two experimental groups

\begin{tabular}{rrrrrrrrr}
\hline & Group & \multicolumn{1}{c}{ S } & \multicolumn{4}{c}{ Skewness } & \multicolumn{2}{c}{ Kurtosis } \\
\cline { 3 - 8 } & & Statistic & Statistic & $\begin{array}{r}\text { Std. } \\
\text { Error }\end{array}$ & Ratio & Statistic & $\begin{array}{c}\text { Std. } \\
\text { Error }\end{array}$ & Ratio \\
\hline Conferencing & Reading & 30 & .177 & .427 & 0.41 & -.560 & .833 & -0.67 \\
& PreWR & 30 & -.234 & .427 & -0.55 & -.140 & .833 & -0.17 \\
& LC & 30 & .005 & .427 & 0.01 & -1.153 & .833 & -1.38 \\
& PostWR & 30 & -.559 & .427 & -1.31 & .380 & .833 & 0.46 \\
& Proficiency & 30 & .148 & .427 & 0.35 & -.733 & .833 & -0.88 \\
& Reading & 30 & .479 & .427 & 1.12 & -.558 & .833 & -0.67 \\
& PreWR & 30 & .098 & .427 & 0.23 & -1.149 & .833 & -1.38 \\
& LC & 30 & -.188 & .427 & -0.44 & -.317 & .833 & -0.38 \\
& PostWR & 30 & -.080 & .427 & -0.19 & -1.405 & .833 & -1.69 \\
& Proficiency & 30 & .069 & .427 & 0.16 & -.470 & .833 & -0.56 \\
\hline
\end{tabular}

The results of the independent $t$-test $(\mathrm{t}(58)=$ $.16 p>.05, \mathrm{r}=.021$ representing a weak effect size) showed that there was not any significant difference between two groups' mean score on the PET test (Table 3). As a result, it can be concluded that the two groups were homogeneous regarding their general language proficiency prior to the treatment. 
Table 3. Independent samples test

\begin{tabular}{|c|c|c|c|c|c|c|c|c|c|}
\hline & \multicolumn{2}{|c|}{$\begin{array}{l}\text { Levene's Test } \\
\text { for Equality } \\
\text { of Variances }\end{array}$} & & & & & \multicolumn{3}{|c|}{$t$-test for Equality of Means } \\
\hline & \multirow[t]{2}{*}{$\mathrm{F}$} & \multirow[t]{2}{*}{ Sig. } & \multirow[t]{2}{*}{$\mathrm{T}$} & \multirow[t]{2}{*}{ Df } & \multirow[t]{2}{*}{$\begin{array}{r}\text { Sig. } \\
(2- \\
\text { tailed) }\end{array}$} & \multirow[t]{2}{*}{$\begin{array}{r}\text { Mean } \\
\text { Difference }\end{array}$} & \multirow[t]{2}{*}{$\begin{array}{l}\text { Std. Error } \\
\text { Difference }\end{array}$} & \multicolumn{2}{|c|}{$\begin{array}{r}95 \% \text { Confidence } \\
\text { Interval of the } \\
\text { Difference }\end{array}$} \\
\hline & & & & & & & & Lower & Upper \\
\hline $\begin{array}{r}\text { Equal } \\
\text { variances } \\
\text { assumed }\end{array}$ & 2.151 & .148 & .158 & 58 & .875 & .267 & 1.689 & -3.11 & 3.64 \\
\hline $\begin{array}{r}\text { Equal } \\
\text { variances } \\
\text { not } \\
\text { assumed }\end{array}$ & & & .158 & 55.826 & .875 & .267 & 1.689 & -3.11 & 3.65 \\
\hline
\end{tabular}

As reported in Table 3, it should be pointed out that: a) The assumption of homogeneity of variances was met (Levene's $\mathrm{F}=2.15, \mathrm{P}>.05$ ). Therefore, the first row was reported; and b) The negative lower bound value of $95 \%$ confidence interval, i.e. -3.11 indicated that the difference between the two groups' means on the PET can be zero.

To address the research question, an analysis of covariance (ANCOVA) was run to compare the oral conferencing and collaborative writing groups' mean scores on the writing posttest while controlling for the potential effects of participants' initial writing ability (the pretest). The ANCOVA has two main assumptions; homogeneity of regression slopes and linear relationship between the dependent variable and the covariate.

The assumption of homogeneity of regression slopes assumes that the relationship between the dependent variable (posttest of writing) and covariate (pretest of writing) shows the same regression slopes across the two groups. The regression line for collaborative writing group and oral conferencing group did not show any interaction, i.e. they did not cross each other (Figure 1). Based on these results, it can be concluded that the assumption of homogeneity of regression slopes was met.

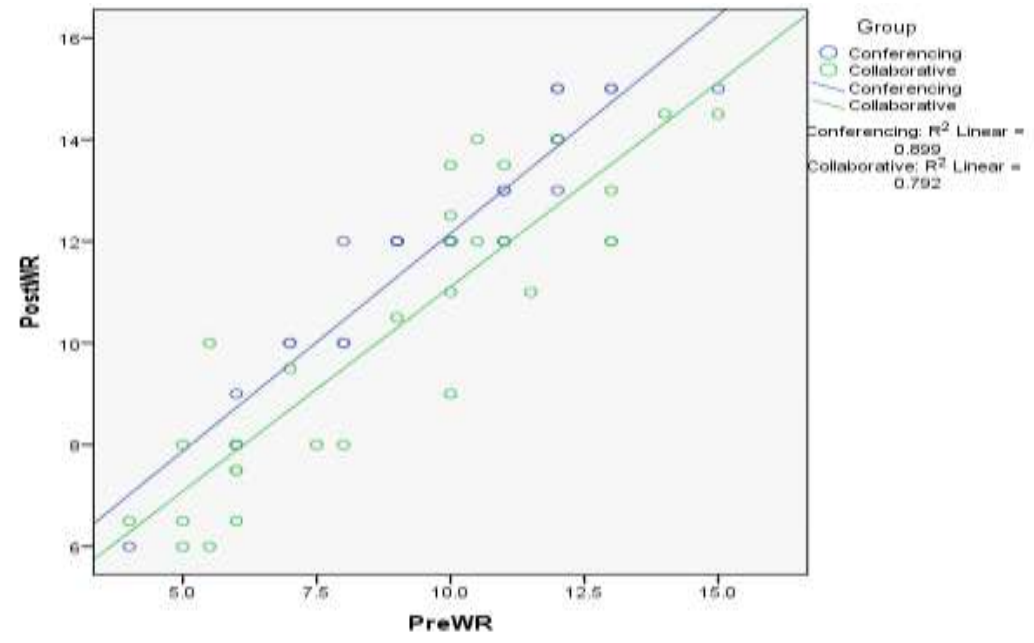

Figure 1. Homogeneity of regression slopes; posttest of writing by groups controlling for pretest

The linear relationship between the dependent variable and covariate can be tested by examining the spread of dots around the diagonals. If the dots spread around the diagonal, it can be concluded that the second assumption is also met. The spread of dots for both groups were close to the diagonals (Figure 2). 


\section{Collaborative Writing}

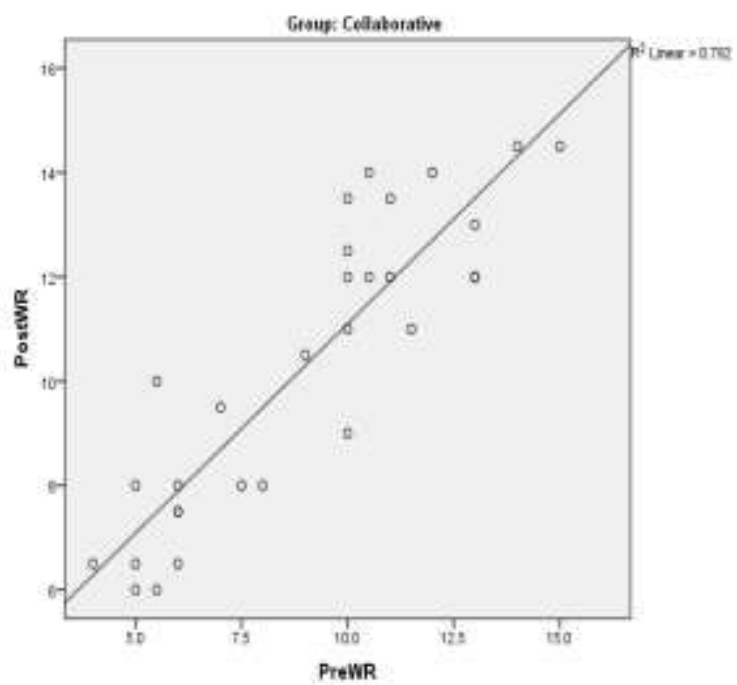

Groups

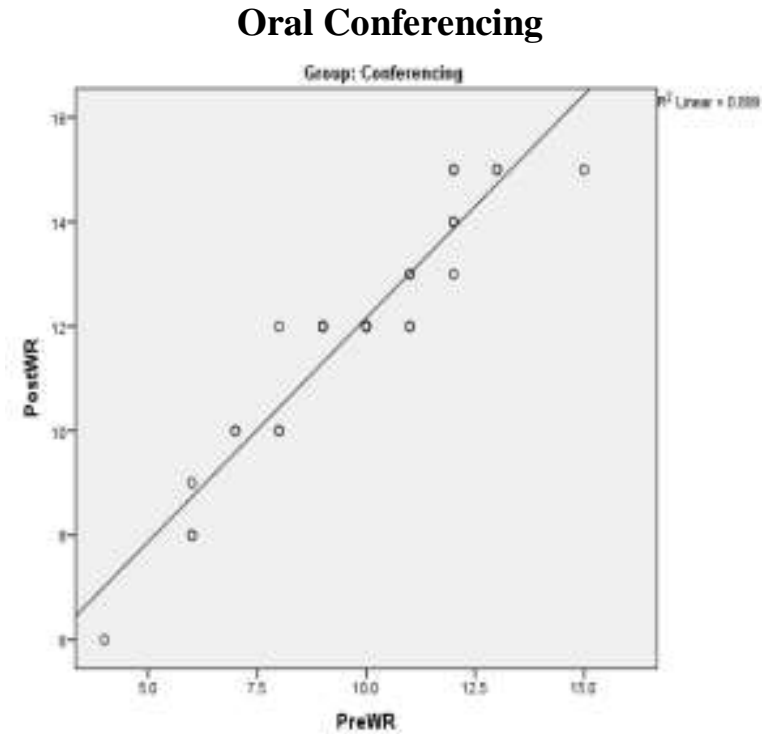

Figure 2. Assumption of linear relationship between dependent variable and covariate

Before discussing the results of the ANCOVA, it should be stated that the assumption of homogeneity of variances was not met (Levene's $\mathrm{F}=8.93, \mathrm{P}<.05)$. As noted by Bachman (2005), Filed (2013) and Pallant (2011) in case the sample size is equal, there is no need to worry about the violation of this assumption.

As displayed in Table 4, the oral conferencing group $(\mathrm{M}=11.61, \mathrm{SE}=.19)$ had a higher mean than the collaborative writing group $(\mathrm{M}=10.58, \mathrm{SE}=.19)$ on the posttest of writing after removing the effect of pretest.

Table 4. Descriptive statistics, posttest of writing by groups controlling for pretest

\begin{tabular}{ccrrr}
\hline Group & Mean & $\begin{array}{r}\text { Std. } \\
\text { Error }\end{array}$ & $95 \%$ & $\begin{array}{r}\text { Confidence } \\
\text { Interval }\end{array}$ \\
\cline { 3 - 5 } & & & $\begin{array}{r}\text { Lower } \\
\text { Bound }\end{array}$ & $\begin{array}{r}\text { Upper } \\
\text { Bound }\end{array}$ \\
\hline Conferencing & $11.612^{\mathrm{a}}$ & .193 & 11.225 & 11.998 \\
Collaborative & $10.588^{\mathrm{a}}$ & .193 & 10.202 & 10.975 \\
\hline
\end{tabular}

a. Covariates appearing in the model are evaluated at the following values: PreWR $=9.35$.

The results of ANCOVA $(\mathrm{F}(1,57)=13.93$, $\mathrm{P}<.05$, Partial $\eta^{2}=.19$ representing a large effect size) confirmed the existence of a significant difference between the mean scores of the two groups on the posttest (Table 5 and
Figure 3). Thus, the null-hypothesis stating that "There is no significant difference between the effect of oral conferencing and collaborative writing on EFL learners' writing ability" was rejected.

Table 5. Tests of between-subjects effects; posttest of writing by groups controlling for pretest

\begin{tabular}{lcccccc}
\hline Source & $\begin{array}{c}\text { Type III } \\
\text { Sum of } \\
\text { Squares }\end{array}$ & Df & $\begin{array}{c}\text { Mean } \\
\text { Square }\end{array}$ & F & Sig. & $\begin{array}{c}\text { Partial Eta } \\
\text { Squared }\end{array}$ \\
\hline Pretest & 315.761 & 1 & 315.761 & 284.608 & .000 & .833 \\
Group & 15.455 & 1 & 15.455 & 13.930 & .000 & .196 \\
Error & 63.239 & 57 & 1.109 & & & \\
Total & 7810.000 & 60 & & & & \\
\hline
\end{tabular}

**. Correlation is significant at the 0.01 level (2-tailed) 


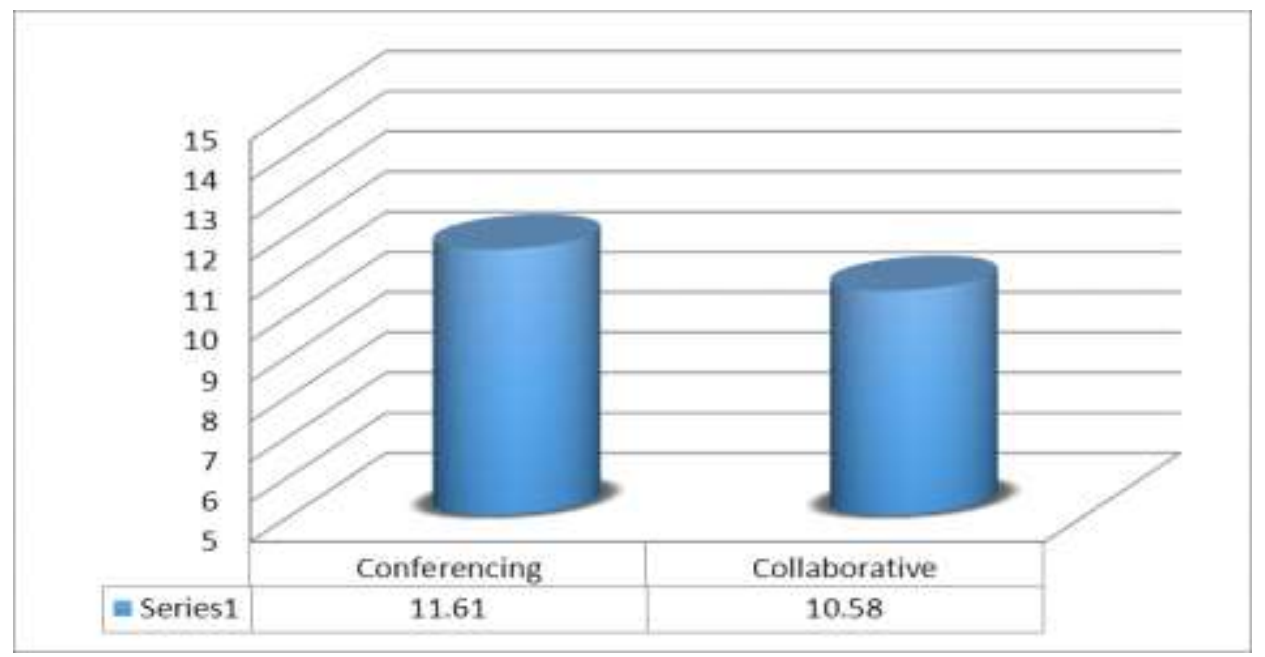

Figure 3. Posttest of writing by groups controlling for pretest

Regarding the question posed in the present study and based on the statistical analysis of the data, there is a significant difference between the effect of oral conferencing and collaborative writing on EFL learners' writing ability. The results of an independent samples $t$-test and analysis of covariance (ANCOVA) revealed that the ability of EFL learners' writing was more affected by applying oral conferencing rather than collaborative writing tasks.

This finding supports previous research. Goldstein and Conrad (1990), for example, examined learner input and negotiation of meaning through oral conferences between one teacher and three learners of an advanced level writing class. They came to the conclusion that learners who negotiated the meaning in the conferences could make better revisions in their drafts, which in turn improved their writing. On the contrary, those learners who were not encouraged to negotiate meaning were inclined towards not making revisions or making very perfunctory revisions that did not result in improved drafts. The finding was also in line with the results of Bitchener, Young, and Cameron (2005) and Wallis (2010) which revealed that a better achievement in writing can be gained through oral conferencing effective feedbacks between the teacher and the student. Furthermore, Pathey-Chavez and Ferries (1997) found that the quality of the writing can be enhanced by oral conferencing sessions which supports the outcome of this study. Besides, this outcome is in line with the findings of Mirzaii (2012) who conducted a study to inspect the impact of providing written corrective feedback through oral conferencing on the writing performance of Iranian intermediate-level EFL learners.

In spite of the significant improvement of participants in the oral conferencing group, the learners who received collaborative writing, also had a better performance in their writing in the posttest (As shown in Table 4), albeit insignificantly. Therefore, this result suggests that collaborative writing can also be useful in teaching writing in some contexts. This result is in line with the finding of a study by Storch (2011), indicating that collaborative tasks are more accurate compared to the tasks carried out individually. In addition, Kuiken and Vedder (2002) investigated the role of group interaction in L2 writing in a cross-sectional study. The result showed that collaborative writing had an overall significant effect on students' L2 writing.

\section{CONCLUSION}

Based on the statistical analysis, it can be concluded that there is a significant difference between the effect of oral conferencing and collaborative writing on EFL learners' writing ability. The results of an independent samples $t$ test and analysis of covariance (ANCOVA) revealed that the ability of EFL learners' writing was more affected by applying oral conferencing rather than collaborative writing tasks. It should be noted that the aforementioned advantages identified for the use of oral conferencing can only be realized when the teacher can effectively carry out the task, i.e. offering encouragement, making specific suggestions, establishing a positive rapport, and having abilities and strategies, such as appropriate interaction, effective monitoring, and supportive evaluation. 
Considering the provision of feedback through oral conferencing, the students can be capable of recognizing their own errors and erroneous areas, planning their learning, and finally evaluating what they have acquired. Also, being engaged in the conferences, students needed to maintain the conversations in order to reflect on the points made by the teacher and the peers; consequently, the speaking ability of the students can be enhanced as well.

Further studies can be carried out to investigate the longer effects of instruction types on writing enhancement. In other words, future studies can adopt a longitudinal design rather than a cross-sectional one. In future research, there is a need to have a larger subject sample size. The more subjects, the greater reliability and validity will result. Besides, the effect of oral conferencing can be investigated on other language skill and sub-skill performance. Apart from corrective feedback some other feedbacks, i.e. electronic feedback's effect can be investigated on writing ability. Learners' individual differences, such as learning styles, creativity, critical thinking, learning strategies, learning aptitude, age, gender, cultural background, background knowledge, and the affective domain are believed to play an important role in learning and using foreign or second language (Nosratinia \& Zaker, 2013, 2014, 2015; Zaker, 2015). Due to some restrictions, these variables have not been taken into account in the present study. Further studies are suggested to investigate these different variables.

\section{REFERENCES}

Bayraktar, Ş. (2009). Pre-service primary teachers' ideas about Lunar Phases. Turkish Science Education, 6(2), 12-23.

Biria, R., \& Jafari, S. (2013). The impact of collaborative writing on the writing fluency of Iranian EFL learners. Journal of Language Teaching and Research, 4(1), 164-175.

Bitchener, J., Young, S., \& Cameron, D. (2005). The effect of different types of corrective feedback on ESL students. Journal of Second Language Writing, 12(3), 191-205.

Brown, J., \& Hudson, T. (1998). The alternatives in language assessment. TESOL Quarterly, 32, 653675 .

Chih, H. K. (2008). Designing an online writing system: Learning with support. ELC Journal, 39(3), 285-299.

Cote, R. (2006). Peer collaboration in the ESL writing classroom: A literature synthesis. Retrieved on May, 2015 from www.u.arizona.edu/ rcote/SLAT596O/Term\%20 Paper.pdf

Cushing Weigle, S. (2002). Assessing writing. Cambridge: Cambridge University Press.

DiCamilla, F. J., \& Anton, M. (1997). Repetition in the collaborative discourse of L2 learners: A Vygotskian perspective. Canadian Modern Language Review, 53(4), 609-633.

Ewert, D. E. (2009). L2 writing conferences: Investigating teacher talk. Journal of Second Language Writing, 18(4), 251-269.

Goldstein, L. M., \& Conrad, S. M. (1990). Student input and negotiation of meaning in ESL writing conferences. TESOL Quarterly, 21, 443-460.

Hayes, J., \& Flower, L. (1980). Identifying the organization of writing processes. In L. Gregg \& E. Steinberg (Eds.), Cognitive processes in writing (pp. 45-57). Hillsdale N. J.: Lawrence Erlbaum Associates.

Hyland, K. (2003). Second language writing. New York: Cambridge University Press.

McCoy, M. K. (2003). Language, math, social studies, and ... worms? Integrating the early childhood curriculum. Dimensions of Early Childhood, 31(2), 3-8.

Mirzaii, M. (2012). Implicit vs. explicit vocabulary learning: Which approach serves long-term recall better? The Southeast Asian Journal of English Language Studies, 18(2), 1-12.

Murray, D. E. (1992). Collaborative learning as literacy event: Implications for ESL instruction. In D. Nunan (Ed.), Collaborative language learning and teaching (pp. 100-117). Cambridge: Cambridge University Press.

Nosratinia, M., \& Zaker, A. (2013, August). Autonomous learning and critical thinking: Inspecting the association among EFL learners. Paper presented at the First National Conference on Teaching English, Literature, and Translation, Shiraz University, Shiraz, Iran. Retrieved from http://www.civilica.com/Paper-TELT01TELT01_226.html.

Nosratinia, M., \& Zaker, A. (2014). Metacognitive attributes and liberated progress: The association among second language learners' critical thinking, creativity, and autonomy. SAGE Open, 4(3), 1-10. doi: 10.1177/2158244014547178.

Nosratinia, M., \& Zaker, A. (2015). Boosting autonomous foreign language learning: Scrutinizing the role of creativity, critical thinking, and vocabulary learning strategies. International Journal of Applied Linguistics and English Literature, 4(4), 86-97. doi: 10.7575/aiac.ijalel.v.4n.4p.86.

Reither, J. A., \& Vipond, D. (1989). Writing as Collaboration. College English, 47, 620-628.

Storch, N. (2005). Collaborative writing: Product, process, and students' reflections. Journal of Second Language Writing, 14(3), 153-173. 


\section{Mania Nosratinia \& Niousha Nikpanjeh}

Promoting foreign language learners' writing: Comparing the impact of oral conferencing and collaborative writing

Storch, N. (2011). Collaborative writing in L2 contexts: Processes, outcomes, and future directions. Annual Review of Applied Linguistics, 31(1), 275-288.

Swain, M., \& Lapkin, S. (1998). Interaction and second language learning: Two adolescent French immersion students working together. Modern Language Journal, 82(3), 320-337.

Vanderburg, R. M. (2006). Reviewing research on teaching writing based on Vygotsky's theories:
What we can learn. Reading and Writing Quarterly, 22, 375-393.

Williams, J. (2002). Undergraduate second language writers in the writing center. Journal of Basic Writing, 21(2), 73-91.

Zaker, A. (2015). EFL learners' language learning strategies and autonomous learning: Which one is a better predictor of L2 skills? Journal of Applied Linguistics-Dubai, 1(1), 27-39. 